\title{
US adopts bar codes for drug products
}

Prescription drugs, biological products and some over-thecounter medications in the US will now be labelled with supermarket-style bar codes - a change the US Food and Drug Administration (FDA) predicts will prevent 500000 medication errors over the next 20 years.

"By giving health care providers a way to check medications and dosages quickly, we create an opportunity to reduce the risks of medication errors that can seriously harm patients," says Tommy Thompson, secretary of US Health and Human Services (HHS).

Manufacturers, repackers, relabellers and private label distributors will have to put bar $\approx$ codes on new products within $\% 60$ days of an FDA approval. They have 2 years to comply हี with the requirement for products already on the market.

Each bar code must contain $\stackrel{\circ}{*}$ the product's National Drug $\stackrel{\circ}{ }$ Code identifier, but may in- clude additional information. Blood products intended for transfusion will include the facility identifier, the lot number relating to the donor, the product code and the donor's blood type and Rh factor. Standardized bar codes will also be required on prescription drug products sold in retail pharmacies. Physicians' drug samples will be exempt.

In a typical dispensing situation, a health care worker will scan the patient's bar coded identification bracelet (which is linked to that patient's computerized medical record), and then the drug bar code. The computer receiving the data will compare the scans to ensure a match. If there is a discrepancy, the computer will issue an error message. A match should ensure the patient gets the right dose, at the right time, administered the right way.

Veterans Administration hospitals using bar codes have already reduced medication errors by up to $85 \%$ over 5 years, says HHS.

"It is our hope that, by using the proven technology of scannable bar codes, we will be able to significantly reduce medication errors," said Dr. John C. Nelson, president of the American Medical Association.

The bar code requirement "represents a tipping point in patient safety," says Ned Simpson, chairperson of the Auto ID and Bar Coding Task Force of the Healthcare Information and Management Systems Society.

Some Canadian hospitals are using bar coding, though it's in its "early stages," says Bonnie Salsman, board member of the newly established Canadian $\mathrm{Pa}$ tient Safety Institute. If appropriately integrated into the system, the practice, she says, does provide safety opportunities. Milan Korcok, Lauderdale-bythe-sea, Fla. 